\title{
Effects of Variety and Curing and Drying Methods on Quality Attributes of Turmeric (Curcuma domestica) Powder
}

\author{
Belay Haile Kebede ${ }^{1}$ \\ https://orcid.org/0000-0002-8337-7756
}

\section{Sirawdink Fikreyesus Forsido ${ }^{1}$}

https://orcid.org/0000-0003-4157-015X

\section{Yetenayet Bekele Tola ${ }^{1}$}

https://orcid.org/0000-0002-8247-4546

\section{Tessema Astatkie ${ }^{2^{*}}$}

https://orcid.org/0000-0002-9779-8789

1 Jimma University, Department of Post-Harvest Management, Jimma, Ethiopia; ${ }^{2}$ Dalhousie University, Faculty of Agriculture, Truro, Nova Scotia, Canada.

Editor-in-Chief: Paulo Vitor Farago

Associate Editor: Jane Manfron Budel

Received: 2020.11.05; Accepted: 2021.05.27.

*Correspondence: astatkie@dal.ca; Tel.: +1-902-893-6694 (T.A.)

\section{HIGHLIGHTS}

- The quality of turmeric powder depends mainly on curing and drying methods

- Curcumin is highly retained in conventional curing and solar tunnel drier

- Open-air sun drying resulted in powder with low ash values and high essential oil

- Improved curing with open-air sun drying provided the maximum oleoresin yield

Abstract: Variety and the method used for curing and drying affect the quality and marketability of processed turmeric (Curcuma domestica) powder. This study was conducted to determine the effects of Variety (Bonga51/71, HT3/2002, and Dame), Curing method (conventional curing (CCM) and improved curing (ICM)), and Drying method (open-air drying (OSD), solar tunnel dryer (STD), and greenhouse solar dryer (GSD)) on the quality attributes (moisture content, total ash, acid-insoluble ash, curcumin, oleoresin, essential oil, and color rating) of turmeric powder using a 3x2x3 factorial design. The results revealed that moisture content was reduced substantially to $7.67 \%$ and $6.5 \%$ for HT3/2002 variety cured with CCM and ICM but dried with STD, respectively; and to $6.67 \%$ and $6.42 \%$ for Dame variety cured/dried/ with ICM/GSD and CCM/STD, respectively. Dame variety cured with ICM and dried with GSD resulted in the lowest total ash $(6.67 \%)$; but it gave the lowest acid-insoluble ash when cured with CCM and dried with OSD (0.993\%) and GSD (0.997\%). The highest curcumin retention (6.99\%) and oleoresin yield (13.88\%) were obtained from Bonga51/71 variety cured with CCM and dried with STD, and Dame variety cured with ICM and dried with OSD, respectively. On the other hand, the highest (6.52\%) essential oil yield was obtained from Bonga51/71 
variety cured with CCM and dried with OSD. In summary, OSD provides the lowest total and acid-insoluble ashes (pharmacognostic parameters of turmeric for different medicinal uses) and the highest oleoresin (contains color, pungency, and flavor constituents of turmeric) in CCM and ICM curing methods, respectively.

Keywords: Curcumin; Postharvest processing; Essential oil; Turmeric quality.

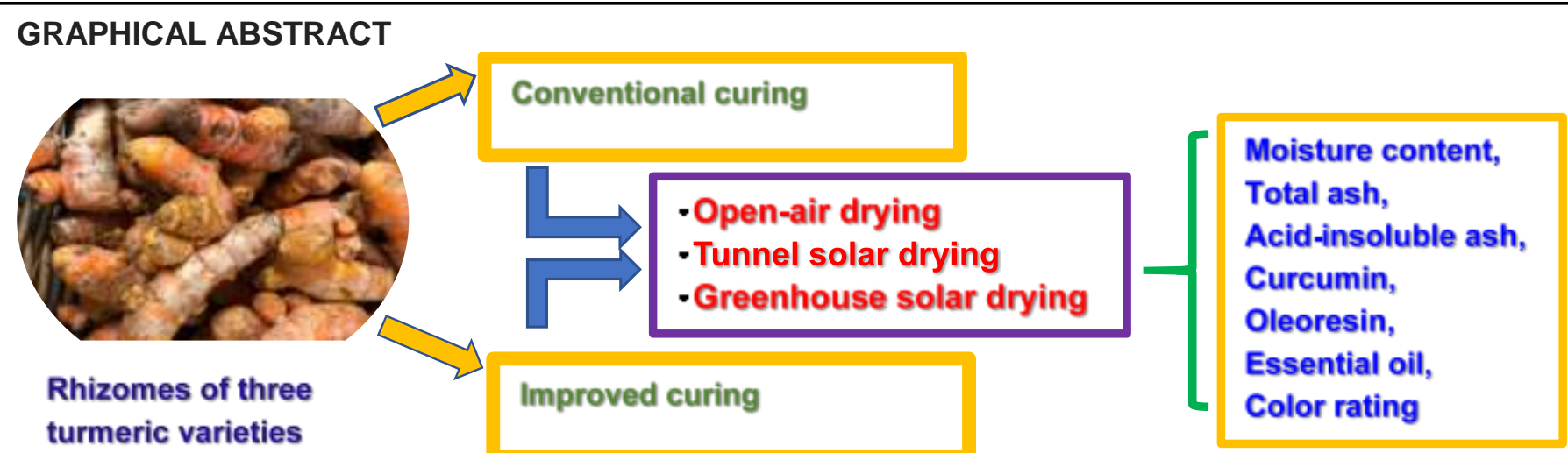

\section{INTRODUCTION}

Among the plants that have medicinal values, the Curcuma genus, which includes 70 known species, have been traditionally used as food preservatives, spices, and for coloring; and are highly significant for their therapeutic potential. Curcuma longa L., or turmeric, is an everlasting herb and member of the Zingiberaceae (ginger) family, which is widely cultivated in South East Asia, mainly in India and China [1]. Turmeric has different names in different parts of the world, many of which are related to its main characteristics and color. In India, it is known as Ranjani, Pita, and Varavarnini, which indicates the bright yellow color of the rhizome; and in Chinese, Jiang-Huang means yellow ginger. Turmeric was also a very important medicinal plant in the Indian and Chinese traditional medicine systems to treat various diseases including diabetic wounds, cough, cardiovascular disease, and hepatic disorders [2].

Curcuminoids and volatile oils are the two active components of turmeric that have shown bioactivities in various studies [2,3]. Curcumin is the principal curcuminoid compound responsible for bright yellow color of turmeric along with demethoxycurcumin and bisdemethoxycurcumin. It has demonstrated a powerful efficacy as an anti-inflammatory, anti-oxidative, anti-Alzheimer, and anti-cancer activities in both preclinical and clinical studies [3]. Essential oil is another major ingredient in turmeric, which accounts for its spicy and aromatic flavor. Studies indicated that the ar-turmerone, $\alpha$-turmerone and $\beta$-turmerone were the biologically active constituents in the essential oil and proved their anti-microbial, anti-oxidative, anti-inflammatory activity, and anti-cancer potentials [2]. As reviewed by Balasubramanian et al. [4], the quality of turmeric depends mainly on postharvest handling and processing practices.

Freshly harvested turmeric rhizomes undergo several postharvest operations, including curing, drying, polishing, and milling, before entering the market as a stable commodity. It has been demonstrated that curing and drying methods have a serious effect on physicochemical quality attributes of turmeric powder [5]. Curing after harvesting is an important postharvest processing operation that involves cooking fresh turmeric rhizomes in boiling water. It is an essential operation before drying to avoid the raw odor, destroy the vitality of fresh rhizomes, yield uniformly colored product, and reduce the drying time [6]. The method of curing turmeric varies from place to place [7]. There are conventional and improved methods of curing turmeric; however, during the conventional method of boiling turmeric, contents might be leached along with water, which in turn lowers curcumin, oleoresin and essential oil contents [8].

Drying is another critically important step during the processing of turmeric with the main aim being reducing moisture from $70-80 \%$ at the time of harvest, to a safe limit of $10 \%$ for grinding or $6 \%$ for safe storage [9]. There are several methods of drying that use different forms of heating; however, solar energy is important for drying agricultural products. Since other conventional sources of energy are in the declining trend in their availability, several researchers reported that solar energy is beneficial for drying agricultural products, particularly in the tropics where good sunshine is available during most of the year and (a) is pollution-free, (b) available at minimal cost, and (c) dries faster [7].

Despite an ever-growing interest and commercial importance of turmeric production in Ethiopia, the final product obtained from smallholder farmers does not perform well in the export market, and it is generally characterized as low quality. The main contributing factor for this low-quality product might be the absence 
of an appropriate processing method to meet the required quality standard [8]. Few researchers studied the impacts of curing and drying methods on turmeric powder $[8,10]$. However, their studies focused on the effect of different drying floor and preparation of rhizomes on the quality of turmeric products using lab scale curing methods. A common approach to evaluating the minimum quality requirement for turmeric powder by many importing countries is based on chemical parameters that can be relevant from food quality and safety points [11]. Therefore, the present study considered the effects of commercial curing methods practiced by smallholders and solar drying methods on the quality attributes of turmeric varieties grown in Ethiopia.

\section{MATERIAL AND METHODS}

\section{Plant materials}

The rhizomes of three turmeric varieties (Bonga51/71, HT3/2002 and Dame) were harvested in January 2019 from Tepi National Spices Research Center, Ethiopia (Latitude of $7^{\circ} 10^{\prime} 54.5^{\prime \prime} \mathrm{N}$ and Longitude $35^{\circ}$ 25.04' 28.2" E and altitude of 1200 m.a.s.l.) after 9 months of planting. The harvesting was decided when the lower leaves of the plant start to dry and turn yellow, and pseudo stems wither. Any leaf scales and long roots were trimmed off and washed with running water to remove mud and dirt particles. The cleaned rhizomes were heaped, covered with leaves, and left to sweat for two days in ambient air.

\section{Curing treatments}

From each variety, $25 \mathrm{~kg}$ of turmeric rhizomes were cured in conventional curing method (CCM) and improved curing method (ICM). In CCM, cleaned rhizomes were boiled in water just enough to immerse them. Boiling stopped when froth comes out (approximately after $30 \mathrm{~min}$ ), and white fumes appear, giving out a typical odor of turmeric. The cooked fingers were let to cool in ambient air. For ICM, cleaned rhizomes were taken in a perforated mild steel drum with an extended parallel handle and immersed in a pan containing plain water. The whole mass was boiled for approximately $25 \mathrm{~min}$ till the fingers became soft. Then perforated mild steel drums containing rhizomes were removed to cool to ambient temperature.

\section{Drying treatments}

Turmeric rhizomes obtained from CCM and ICM were subjected to three different drying methods, open sun drying (OSD) on tarpaulin sheet from 9:00 am to 5:00 pm, in solar tunnel drier (STD), and greenhouse solar drier (GSD). Samples spread on the drying layer at a thickness of $5-7 \mathrm{~cm}$, and approximately $10 \mathrm{~cm}$ was left between randomly assigned samples to avoid samples cross over. Then, the samples were manually stirred in a regular interval (2 hr) for uniform drying. Complete dryness of rhizome was judged when it sounds "metallic twang" upon breaking of dried rhizome following the standards of Indian Ministry of Agriculture [12]. Then, the dried rhizome was grounded into a fine powder with a laboratory model grinder (Retsch GmbH mill model 5657 , Germany). Grounded samples sieved through a $0.50 \mathrm{~mm}$ sieve were stored at $4{ }^{\circ} \mathrm{C}$ after packing in a water and air proof container.

\section{Experimental design and factors}

This experiment was carried out as a $3 \times 2 \times 3$ factorial design as described in Montgomery [13] to study the effects of curing methods and drying methods on the quality of turmeric varieties grown in Ethiopia. There were three levels of Variety (Bonga51/71, HT3/2002, Dame), two levels of Curing method (CCM and ICM), and three levels of Drying method (OSD, STD and, GSD). Each treatment combination was replicated three times. With 18 treatment combinations, the total number of observations for each response variable was 54.

\section{Data measurement}

Official Methods of Analysis of AOAC [14] was used to determine the essential oil content of turmeric powder by hydrodistillation in a modified Clevenger apparatus. The total ash was determined gravimetrically using a furnace (CARBOLITE, S33 6 RB, England) at $550^{\circ} \mathrm{C}$. Acid-insoluble ash content was determined after the total ash was boiled with $2 \mathrm{M}$ of hydrochloric acid for 5 minutes, collected the insoluble matter in a Gooch crucible, washed with hot water, ignited, cooled in a desiccator, and weighed. The moisture content of turmeric powder was estimated by the toluene distillation method and for its oleoresin content by a cold extraction process using the solvent acetone as per the American Spice Trade Association procedure described in [15]. The curcumin constituent was quantitatively determined spectrophotometrically as 
described in [16]. A standard curve was obtained using the standard solution in the range of $1.6-8 \mu / \mathrm{ml}$ $\left(R^{2}=0.992\right)$. Absorbance of these solutions was taken at $425 \mathrm{~nm}$ using UV-Visible spectrophotometry (Model: JASCO V-630, Shimadzu Corporation, Tokyo, Japan) having two matched quartz cells with $1 \mathrm{~cm}$ path length. The rating of reflected color value was correlated with powder, appearance as shown in [17]. Thirty untrained panelists were asked to categorize the color of the powder obtained from different treatment combinations as $1=$ Dull-Yellow; $2=$ Light-Yellow; $3=$ Yellow, or 4=Orange-Yellow.

\section{Statistical analysis}

Measurements on seven response variables (moisture content, total ash, acid-insoluble ash, curcumin, oleoresin, essential oil, and color rating) in three replications and color rating in 30 replications were analyzed as a $3 \times 2 \times 3$ factorial design. The analysis of variance (ANOVA) was completed using the GLM procedure of SAS software [18], and further multiple means comparison was conducted for significant $(P<0.05)$ effects using the LSmeans statement of Proc GLM, and letter groupings were generated at the $5 \%$ level of significance. For each response, the validity of model assumptions on the error terms was verified by examining the residuals as described in [13].

\section{RESULTS AND DISCUSSION}

\section{Moisture content}

Drying was carried out to reduce the moisture content of the samples to nearly the same level. The cured turmeric samples were dried until the rhizomes become hard, brittle, and break with a metallic sound, thereby indicating the completion of the drying process. It was observed that nearly nine more days were required under OSD (19 days) over STD (10 days) to arrive at the drying endpoint. On the other hand, GSD (16 days) was the second-fastest drying method. It seems possible that these differences are due to the different average temperatures recorded in the drying methods during the drying process. It was observed that the average temperature inside the STD was about $19^{\circ} \mathrm{C}$ and $30^{\circ} \mathrm{C}$ higher than in GSD and OSD, respectively.

The findings of the current study are consistent with those of Pochont and coauthors [20], who reported that active (forced convection) mode drying reduces the moisture content and drying time than passive (natural convection) drying and open sun drying. Solar drying systems are mainly categorized into direct, indirect, and mixed-mode drying. They are also classified as active and passive based on the mode of air movement [21]. In this study, STD falls under the active mode of drying and GSD falls under the passive mode of drying.

The three-way interaction effect of Variety, Curing method, and Drying method on the moisture content of turmeric powder was highly significant $(P=0.001$; Table 1$)$. The highest moisture content $(11.58 \%)$ was observed in Bonga51/71 variety cured with ICM and dried with OSD (Table 2). However, this mean moisture content was not significantly different from $11.08 \%, 10.83 \%$, and $10.83 \%$ obtained from Bonga/CCM/OSD, Dame/CCM/OSD, and Dame/ICM/OSD combinations, respectively (Table 2). On the other hand, the Variety/Curing method/Drying method that gave the lowest moisture contents $(6.67 \%, 6.42 \%, 7.67 \%$, and 6.5\%) were Dame/ICM/GSD, Dame/CCM/STD, HT/CCM/STD, and HT/ICM/STD, respectively (Table 2). The other combinations gave moisture contents ranging from $8.25 \%$ to $9.92 \%$.

Table 1. Analysis of variance (ANOVA) $P$-values that show the significance of the main and interaction effects of Variety, Curing method (CM), and Drying method (DM) on moisture content (MC), total ash (TA), acid-insoluble ash (AIA), curcumin, essential oil (EO), oleoresin, and color rating (CR). Significant effects that require multiple means comparison are shown in bold. The last row shows the R-squared values that show the percentage of the total variability explained by the effects in the model.

\begin{tabular}{llllllll}
\hline Source of Variation & MC & TA & AIA & Curcumin & EO & Oleoresin & CR \\
\hline Variety & $<0.001$ & $<0.001$ & $<0.001$ & $<0.001$ & $<0.001$ & $<0.001$ & $<0.001$ \\
CM & 0.287 & 0.107 & $<0.001$ & 0.016 & 0.009 & 0.002 & $<0.001$ \\
DM & $<0.001$ & $<0.001$ & $<0.001$ & 0.017 & $<0.001$ & 0.044 & $<0.001$ \\
Variety ${ }^{*} \mathrm{CM}$ & 0.259 & 0.010 & $<0.001$ & 0.111 & $<0.001$ & $<0.001$ & 0.155 \\
Variety ${ }^{*} \mathrm{DM}$ & 0.001 & 0.015 & $<0.001$ & 0.093 & $<0.001$ & $<0.001$ & $<0.001$ \\
$\mathrm{CM}^{*} \mathrm{DM}$ & 0.043 & 0.289 & 0.001 & 0.004 & 0.002 & 0.001 & $<0.001$ \\
Variety $^{*} \mathrm{CM}{ }^{*} \mathrm{DM}$ & $\mathbf{0 . 0 0 1}$ & $<0.001$ & $\mathbf{0 . 0 0 1}$ & $\mathbf{0 . 0 0 1}$ & $<\mathbf{0 . 0 0 1}$ & $\mathbf{0 . 0 0 2}$ & $\mathbf{0 . 0 2 5}$ \\
R-squared $(\%)$ & 89.4 & 90.9 & 95.6 & 84.8 & 99.2 & 95.6 & 49.6 \\
\hline
\end{tabular}


The European Spice Association [19] quality minima document indicates that the benchmark moisture content for turmeric powder is less than $10 \%(\mathrm{w} / \mathrm{w})$. Low moisture content is required during storage and transportation until final use to avoid later mold infections and growth in the product [11], which might be associated with relatively lower water activity. On the other hand, extreme reduction of moisture levels might lead to loss of flavor of the spices after grinding [22], which might be because of exposure of the essential oils to ambient air oxidation due to removal of monolayer water due to extreme drying. Hence, it is necessary to select the available drying methods to achieve the standard final moisture content of turmeric rhizomes and powder for better shelf life.

Table 2. Mean moisture content (MC), total ash (TA), acid-insoluble ash (AIA), curcumin, essential oil (EO), oleoresin (Oleo), and color rating (CR) obtained from the 18 combinations of Variety, Curing method (CM), and Drying method (DM). Means sharing the same letter are not significantly different.

\begin{tabular}{|c|c|c|c|c|c|c|c|c|c|}
\hline Variety & $\mathrm{CM}$ & DM & MC (\%) & TA (\%) & AIA (\%) & $\begin{array}{l}\text { Curcumin } \\
(\%)\end{array}$ & EO (\%) & Oleo (\%) & CR \\
\hline Bonga51/71 & CCM & GSD & 9.00 cde & $8.75^{\text {cde }}$ & $1.407 \mathrm{de}$ & 5.52 defg & $6.25^{a b c}$ & $13.31^{a b c}$ & $1.54^{h}$ \\
\hline Bonga51/71 & CCM & OSD & $11.08 \mathrm{ab}$ & $9.55^{a b}$ & 1.490 cde & 5.74 bcdef & $6.52^{a}$ & $13.61^{a b}$ & $2.83^{\mathrm{cd}}$ \\
\hline Bonga51/71 & CCM & STD & 8.50 de & $9.82^{a}$ & $1.700 \mathrm{ab}$ & $6.99^{a}$ & $6.27^{a b c}$ & $13.83^{a}$ & $3.06 \mathrm{abc}$ \\
\hline Bonga51/71 & $\mathrm{ICM}$ & GSD & 8.67 cde & $9.25^{a b c}$ & $1.507 \mathrm{~cd}$ & 5.77 bcde & $6.27^{a b c}$ & $13.26^{a b c}$ & 2.43 def \\
\hline Bonga51/71 & ICM & OSD & $11.58^{a}$ & $9.17^{\mathrm{bcd}}$ & $1.690 \mathrm{ab}$ & $5.65^{\text {cdef }}$ & $6.37^{a b}$ & $10.82^{d}$ & $3.10^{a b c}$ \\
\hline Bonga51/71 & $\mathrm{ICM}$ & STD & 8.58 cde & $9.18 \mathrm{bcd}$ & $1.820^{a}$ & 5.46 efg & $6.13^{b c}$ & $12.42^{c}$ & $3.41^{a b}$ \\
\hline Dame & CCM & GSD & 8.67 cde & $7.57^{\mathrm{gh}}$ & $0.997^{i}$ & $5.65^{\text {cdef }}$ & $5.75^{d}$ & $13.66^{a b}$ & $2.45^{\text {def }}$ \\
\hline Dame & CCM & OSD & $10.83 a b$ & $7.17^{\mathrm{h}}$ & $0.993^{i}$ & $6.69^{a}$ & $6.37^{a b}$ & $13.42 a b c$ & 2.97 bc \\
\hline Dame & CCM & STD & $6.42^{f}$ & 8.25 ef & $1.113 \mathrm{hi}$ & $6.64^{a}$ & $5.13^{e}$ & $12.61 \mathrm{bc}$ & $3.46 \mathrm{ab}$ \\
\hline Dame & $\mathrm{ICM}$ & GSD & $6.67^{f}$ & $7.83^{\mathrm{fg}}$ & $1.700 \mathrm{ab}$ & $6.45^{a b}$ & $6.35^{a b}$ & $13.41^{a b c}$ & 2.80 cde \\
\hline Dame & ICM & OSD & $10.83^{a b}$ & $7.83^{\mathrm{fg}}$ & 1.367 ef & $6.27 \mathrm{abcd}$ & $6.35^{a b}$ & $13.88^{a}$ & $3.44^{a b}$ \\
\hline Dame & $\mathrm{ICM}$ & STD & 8.25 de & 8.58 de & $1.577 \mathrm{bc}$ & $6.36^{a b c}$ & $6.03^{c}$ & $12.66^{b c}$ & $3.51^{a}$ \\
\hline HT3/2002 & CCM & GSD & 8.83 cde & $8.75^{\mathrm{cde}}$ & $1.253^{f g}$ & $5.33^{\mathrm{efg}}$ & $3.82^{f}$ & $8.93^{\mathrm{g}}$ & $1.41^{\mathrm{h}}$ \\
\hline HT3/2002 & CCM & OSD & $9.92^{b c}$ & $8.75^{\text {cde }}$ & $1.227^{\mathrm{gh}}$ & $5.05^{\mathrm{efg}}$ & $3.92^{f}$ & $10.58 \mathrm{de}$ & $2.36^{\text {efg }}$ \\
\hline HT3/2002 & CCM & STD & 7.67 ef & $8.77^{\text {cde }}$ & $1.423 \mathrm{de}$ & 5.12 efg & $3.90^{f}$ & $9.39^{\mathrm{fg}}$ & $1.99 \mathrm{~g}$ \\
\hline HT3/2002 & $\mathrm{ICM}$ & GSD & $8.75^{\text {cde }}$ & $8.67^{\text {cde }}$ & $1.537^{\mathrm{cd}}$ & $4.80^{\mathrm{g}}$ & $3.67^{f}$ & 9.84 ef & $2.02^{\mathrm{g}}$ \\
\hline HT3/2002 & ICM & OSD & $9.42^{\mathrm{cd}}$ & 8.33 ef & $1.237^{\text {fgh }}$ & $4.86^{g}$ & $3.82^{f}$ & 9.83 efg & $2.30^{\mathrm{fg}}$ \\
\hline HT3/2002 & ICM & STD & $6.50^{f}$ & $9.63^{a b}$ & $1.587 \mathrm{bc}$ & $4.99 \mathrm{fg}$ & $3.77^{f}$ & $9.20^{\mathrm{fg}}$ & $2.33^{\mathrm{fg}}$ \\
\hline
\end{tabular}

Total Ash (TA) and Acid-Insoluble ash (AIA)

The ANOVA results shown in Table 1 reveal that the 3-way interaction effect of Variety, Curing method, and Drying method was significant on both total ash and acid-insoluble ash of turmeric. The results in Table 2 show that the highest total ash (9.82\%) was obtained from Bonga51/71 variety in CCM and STD whereas the lowest mean (6.67\%) was obtained from Dame variety cured in ICM and dried in GSD. This could be explained by the significant diversity in total ash content among turmeric varieties reported in [23]. Furthermore, the removal of moisture at elevated temperature leads to nutrient density, which is directly related with total ash. As noted in [24], drying of ginger in solar system resulted in the maximum total ash contents that could be a potential source of minerals.

The total ash and acid-insoluble ash were determined as part of pharmacognostic parameters to standardize turmeric varieties for multiple medicinal uses. Total ash includes "physiological ash", which is derived from the plant tissue itself, and "non-physiological ash" from extraneous matter whereas, acidinsoluble ash limit was imposed specially incase where foreign silica might be present [23]. As Shukla and coauthors [25] noted, the lower value of acid-insoluble ash can be considered as an indicative of the presence of a small amount of non-physiological components like silica and silicates. Higher value of acid-soluble ash shows larger amount of acid soluble compounds like oxalates, carbonates, phosphates, and oxides, respectively [25].

The mean acid-insoluble ash obtained from the combinations of Variety, Curing method, and Drying method are shown in Table 2. The highest (1.82\%) mean acid-insoluble ash was obtained from Bonga51/71 variety cured with ICM and dried with STD whereas the lowest $(0.993 \%$ and $0.997 \%)$ were obtained from Dame variety cured with CCM but dried with OSD and GSD, respectively. In addition to variety variations in the absorption of organic materials, the low acid-insoluble ash might be due to leaching of inorganic materials to boiling medium in conventional curing method. The European Spice Association [19] suggested that total 
ash and acid-insoluble ash values of turmeric powder should be less than $9 \%$ and $2.5 \%$, respectively. While the highest total ash $(9.82 \%)$ is a bit above the limit, all acid-insoluble ash values were below the limit suggested by the European Spice Association. Drying of turmeric rhizomes at elevated temperature may dissipate the physiologically active constituent and retain the maximum non-physiological components contributing to the acid-insoluble ash. Comparison with the literature is complicated because most papers claim adulteration and environmental conditions for variations in ash values. For example, the highest total ash content (8.9\%) reported by Nagarnaik and coauthors [26] for turmeric powder from the market was due to inorganic contaminants such as carbonates, phosphates, and silicates in the sample. Ashraf and coauthors [23] indicated that the geographical features of the cultivating regions affect the total ash and acid-insoluble ash of turmeric samples.

\section{Curcumin}

Curcumin, commonly called diferuloylmethane, is a compound of interest in turmeric rhizomes that gives a yellow color for turmeric products. It is being recognized worldwide for its multiple health benefits [27]. In the present study, the three-way interaction effect of Variety, Curing method, and Drying method on curcumin content of turmeric was highly significant $(P=0.001$; Table 1). As shown in Table 2, the highest curcumin contents that are not significantly different from each other were found in the CCM and STD treatment combination for Dame (6.64\%) and Bonga51/71 (6.99\%) varieties, respectively; and the treatment combination of Dame variety, ICM, and GSD (6.45\%), and Dame variety, CCM, and OSD (6.69\%). On the other hand, HT3/2002 cured with ICM and dried with GSD (4.80\%) or OSD (4.86\%) gave the lowest curcumin contents. Generally, the lowest curcumin contents were obtained from HT3/2002 variety regardless of the drying and curing method used. This discrepancy in curcumin retention between turmeric varieties with similar postharvest operations may be due to genetic factors indicating that phytochemicals are attributes of biosynthetic gene expression pathways [28]. Several studies have already reported the presence of variations in curcumin content among different turmeric varieties. Sinkar and coauthors [29] reported that the curcumin content of turmeric varieties cultivated in the Konkan region of Maharashtra in India varied from $1.3 \%$ to $4.9 \%$. Shashidhar and coauthors [30] reported that curcumin concentrations of 18 varieties in the northern dry zone of Karnataka ranged from $2.1 \%$ to $4.7 \%$. In contrast, Shannon and coauthors [31] reported significant differences in curcumin concentrations of four turmeric varieties in Alabama, USA.

Our results share several similarities with Jayashree and coauthors [6] findings, who reported that the maximum curcumin retention was obtained from turmeric samples boiled in the traditional curing method. Conversely, Lokhande and coauthors [5] reported that the higher retention of curcumin was observed in samples cured with an improved method. In their experiments cleaned fingers were added in perforated galvanized mild steel drums, immersed in a kettle containing alkaline solution $(0.1 \%$ Sodium bicarbonate) and boiled till the fingers became soft. The resulting maximum curcumin retention was due to the presence of alkali at a higher temperature that could favor the formation of ferulic acid and feruloilmethane [32]. It was reported that part of the feruloilmethane formed during alkali degradation can participate in condensation reactions originating from compounds of yellow to yellow-brownish color, which could affect the spectrophotometric determination of curcuminoid pigment [32].

A negative impact of shade drying (GSD) than STD on curcumin concentration was also reported previously [33]. The GSD took 16 days, followed by OSD, and the color of GSD dried samples appeared dull due to a lower rate of moisture loss with a natural convection. This long drying duration could result in reduction of curcumin concentration due to heat degradation.

\section{Essential oil (EO)}

The three-way interaction effect was also significant $(P<0.001)$ on EO yield as well (Table 1$)$. As shown in Table 2, turmeric powder obtained from Bonga51/71 variety exhibited the highest EO yield $(6.52 \%)$ when cured with CCM and dried with OSD. However, this mean value was not significantly different from 7 other combinations whose EO yield ranged from $6.25 \%$ to $6.37 \%$ (Table 2). Lower EO yields, ranging from $3.67 \%$ to $3.90 \%$, were obtained from the HT3/2002 variety processed with the combinations of the two curing and the three drying methods (Table 2). These results are similar to what was reported previously [34]. When turmeric rhizomes dried to the minimum moisture content, the dried sample appears to be more fibrous and harder, and thus it is more difficult to break and grind. Upon grinding, the spices get warmer, resulting in a loss of volatile oils [4]. This may be a possible reason for the low yield of volatile oil in samples dried in STD. This result does not support a previous [5] argument that curing and drying methods (Sun drying and 
Mechanical drying) do not affect essential oil content because the essential oil of turmeric had a higher boiling point. But Dobreva and coauthors [35] reported that effective treatment combinations reduce the surface tension of the epidermal plant glands and induce a significant increase in oil yields.

\section{Oleoresin}

Oleoresin is commonly marketed as spice drops and contains the total color, pungency, and flavor constituents of turmeric. It is a mixture of compounds, namely curcumin, volatile oil and other active ingredients, non-volatile fatty and resinous material extractable by organic solvents, used singly, sequentially or in combination [3]. The results of the present study reveal significant differences among varieties, depending on the curing method and the drying method (three-way interaction effect) in terms of oleoresin yield of turmeric samples (Table 1). The multiple means comparison of the mean oleoresin content of turmeric obtained from the treatment combinations of the three factors are shown in Table 2. The highest oleoresin yield (13.88\%) was obtained from Dame variety processed with ICM and OSD. In contrast, the lowest oleoresin yield (8.93\%) was obtained from HT3/2002 variety cured with CCM and dried with GSD (Table 2). The results show that much higher mean values of oleoresin yield were obtained in this study compared to what was reported by Kifelew and coauthors [36]. The authors reported mean oleoresin yields ranging from $6 \%$ to $7.53 \%$ obtained from the same varieties (Bonga51/71, HT3/2002, and Dame), but grown at different locations.

To determine the effects of drying methods on the quality of turmeric powder, Padma and coauthors [37] compared OSD and GSD on different floors. They obtained higher oleoresin content from GSD compared to that from OSD on the same floor. Singh and coauthors [9] postulated that the variation in oleoresin content of turmeric samples depends mainly on the raised average temperature in the drying system. Jayashree and coauthors [6] reported variations in oleoresin yield from turmeric samples due to differences in the curing treatment. They reported that the lowest value $(10.26 \%)$ was obtained from turmeric samples steam cured in TNAU boiler, while the traditional curing method in plain water provided the highest $(10.51 \%)$ oleoresin yield.

\section{Color rating}

Unlike the model of the other response variables where the coefficient of determination (R-squared) values were over $85 \%$ (the effects in the model explained at least $85 \%$ of the total variability), the R-squared value for color rating was only $50 \%$ (Table 1). This suggests that there are other sources of variability including factors associated with the panelists. Keeping this in mind, the three-way interaction effect on the color rating was also significant $(P=0.025$; Table 1). Higher color ratings, ranging from 3.06 to 3.51 (between yellow and orange-yellow), were obtained from Bonga51/71 and Dame varieties cured with ICM and dried with OSD or STD, and cured with CCM and dried with STD (Table 2). The lower mean color ratings (1.41 and 1.54, between dull-yellow and light-yellow) were observed in HT3/2002 and Bonga51/71 varieties, both cured with CCM and dried with GSD (Table 2).

Although our color rating results differ slightly from those of Mariam and coauthors [10] who reported that drying on raised bed improves the color value of turmeric samples due to aeration in the wire mesh, GSD is responsible for the lower value of color rating in our study. The observed lower value of color rating in GSD corroborates the ideas of Lokhande and coauthors [5], who argued that a lower rate of moisture loss leads to a dull appearance of turmeric powder in shade drying. Some studies reported that high temperatures experienced in blanching followed by sun drying causes thermal degradation of curcumin [34], which implies the presence of a synergetic effect of curing and drying methods on reflected color of turmeric powder.

\section{CONCLUSION}

The results obtained from this study show that STD is the best dryer to reduce the moisture content of turmeric to the required level in a short period, irrespective of curing method. Processing of turmeric in CCM and STD retains the maximum curcumin content of Bong51/71 and Dame varieties. Therefore, STD is recommended for commercial-scale processing of turmeric rhizomes. The widely used turmeric processing method in the rural areas of the developing countries, i.e., CCM with OSD, provides the highest yields of essential oil and the lowest values of total ash and acid-insoluble ash. Taken together, the findings of this study can enable turmeric producers to select an appropriate treatment combination to produce turmeric products that meet the quality requirements of the fabric, pharmaceutical and food industries.

Conflicts of Interest: The authors declare no conflict of interest. 


\section{REFERENCES}

1. El-Kenawy, A.E.-M.; Hassan, S.M.A.; Mohamed, A.M.M.; Mohammed, H.M.A.M. Tumeric or Curcuma longa Linn. In: Nabavi SM, Sanches Silva A, editors. Nonvitamin and Nonmineral Nutritional Supplements. Elsevier Inc.: London, UK; 2019. p. 447-53.

2. Meng FC, Zhou YQ, Ren D, Li T, Lu JJ, Wang RB, Wang CM, Lin LG, Zhang XQ, Ye WC, et al. Turmeric: A review of its chemical composition, quality control, bioactivity, and pharmaceutical application. In: Alexandru MG, Alina $\mathrm{MH}$, editors. Handbook of Food Bioengineering. Academic Press: Cambridge, MA, USA; 2018. p. 299-350.

3. Rolfe V, Mackonochie M, Mills S, MacLennan E. Turmeric/curcumin and health outcomes: A meta-review of systematic reviews. Eur. J. Integr. Med. 2020; 40: 101252.

4. Balasubramanian S, Roselin P, Singh KK, Zachariah J, Saxena SN. Postharvest processing and benefits of black pepper, coriander, cinnamon, fenugreek, and turmeric spices. Crit. Rev. Food Sci. Nutr. 2016; 56(10): 1585-607.

5. Lokhande SM, Kale RV, Sahoo AK, Ranveer RC. Effect of curing and drying methods on recovery, curcumin and essential oil content of different cultivars of turmeric (Curcuma longa L). Int. Food Res. J. 2013; 20(2): 745-9.

6. Jayashree E, Zachariah T, Rakhi R. Comparison of quality of dry turmeric (Curcuma longa) produced by slicing and other curing methods. J. Spices Aromat. Crops. 2018; 27: 138-44.

7. Padma M, Reddy BS, Madhava M. Some studies on curing and drying characteristics of turmeric rhizomes. Internat. J. Proc. \& Post Harvest Technol. 2016; 7(1): 151-6.

8. Hirko B, Abera S, Mitiku H. Effect of Curing and Drying Methods on the Biochemical Quality of Turmeric (Curcuma longa L.) Rhizome Grown in South Western Ethiopia. Med. Aromat. Plants (Los Angeles) 2020; 9(5): 357.

9. Singh G, Arora S, Kumar S. Effect of mechanical drying air conditions on quality of turmeric powder. J. Food Sci. Technol. 2010; 47: 347-50.

10. Mariam LW, Mohamed A, Tilahun D. Effect of rhizome types, drying thickness and drying materials on the quality of turmeric (Curcuma longa L.) in Tepi, South Western Ethiopia. Agric. Res. Technol. 2017; 11(2): 555809.

11. Schaarschmidt S. Public and private standards for dried culinary herbs and spices - Part I: Standards defining the physical and chemical product quality and safety. Food Cont. 2016; 70: 339-49.

12. Mazaud F, Röttger A, Steffel K. Turmeric: Post-Production Management. Food and Agriculture Organization of the United Nations (FAO), AGST; 2004.

13. Montgomery DC. Design and analysis of experiments, 10th edn. John Wiley \& Sons, New York; 2020.

14. Association of Official Analytical Chemists (AOAC). Official methods of analysis Vol. 11, 16th edn. AOAC, Arlington, VA; 1995.

15. Datta PR. Official Analytical Methods of the American Spice Trade Association, 4th edn. ASTA Inc., Englewood Cliffs, New Jersey; 1997.

16. Pawar $\mathrm{H}$, Karde M, Mundle N, Jadhav $P$, Mehra K. Phytochemical evaluation and curcumin content determination of turmeric rhizomes collected from Bhandara District of Maharashtra (India). Med. Chem. 2014; 4(8): 588-91.

17. Raghavan S. Handbook of spices, seasonings, and flavorings, 2nd ed. CRC Press, New York; 2006.

18. SAS Institute Inc. SAS/STAT 9.4 User's Guide. SAS Institute Inc., Cary, NC; 2014.

19. European Spice Association. European spice association quality minima document. Bonn, Germany; 2004.

20. Pochont NR, Mohammad MN, Pradeep BT, Kumar PV. A comparative study of drying kinetics and quality of Indian red chilli in solar hybrid greenhouse drying and open sun drying. Mater. Today: Proceedings 2020; 21: 286-90.

21. Udomkun P, Romuli S, Schock S, Mahayothee B, Sartas M, Wossen T, Njukwe E, Vanlauwe B, Müller J. Review of solar dryers for agricultural products in Asia and Africa: An innovation landscape approach. J. Envir. Mgm. 2020; 268: 110730.

22. Panda H. Handbook on spices and condiments (cultivation, processing and extraction). Asia Pacific Business Press Inc., Delhi, India; 2010.

23. Ashraf $\mathrm{K}$, Jameel M, Mujeeb M. Evaluation of pharmacognostical variations in eight accession of Curcuma longa L. Int. J. Green Pharm. 2018; 12(1): 268-73.

24. Ajayi OA, Ola OO, Akinwunmi OO. Effect of drying method on nutritional composition, sensory and antimicrobial properties of Ginger (Zinginber officinale). Int. Food Res. J. 2017; 24(2): 614-20.

25. Shukla RK, Painuly D, Porval A, Shukla A. Proximate analysis, nutritional value, phytochemical evaluation, and biological activity of Litchi chinensis Sonn. leaves. J. Herbs Spices Med. Plants. 2014; 20(2): 196-208.

26. Nagarnaik M, Sarjoshi A, Bodkhe A, Khanal B, Pise M, Pandya G. Characterization of active constituents in Turmeric powder and validation of method for curcumin in samples. Asian J. Res. Chem. 2015; 8(10): 643-7.

27. Kocaadam B, Şanlier N. Curcumin, an active component of turmeric (Curcuma longa), and its effects on health. Crit. Rev. Food Sci. Nutr. 2017; 57(13): 2889-95.

28. Ayer DK. Breeding for quality improvement in turmeric (Curcuma longa L.): a review. Adv. Plants Agric. Res. 2017; 6(6): 1-4. 
29. Sinkar PV, Haldankar PM, Ranpise RK, Joshi GD, Mahale BB. Preliminary evaluation of turmeric (Curcuma longa L.) varieties at Konkan region of Maharashtra. J. Spices Aromat. Crops. 2005; 14(1): 28-33.

30. Shashidhar MD, Hegde NK, Hiremath JS, Kukunoor L, Srikantprasad D, Patil RT. Evaluation of turmeric (Curcuma longa L.) genotypes for yield, curcumin and essential oil content in northern dry zone of Karnataka. J. Pharmacogn. Phytochem. 2018; 3: 130-4.

31. Shannon DA, van Santen E, Salmasi SZ, Murray TJ, Duong LT, Greenfield JT, Gonzales T, Foshee W. Shade, Establishment Method, and Varietal Effects on Rhizome Yield and Curcumin Content in Turmeric in Alabama. Crop Sci. 2019; 59(6): 2701-10.

32. Tonnesen HH, Karlsen J. Studies on curcumin and curcuminoids. Vi. Kinetics of curcumin degradation in aqueous solution. Z. Lebensm. Unters. Forsch. 1985; 180: 402-4.

33. Raza A, Ali A, Yusof YA, Nasir A, Muneer S. Effect of different drying treatments on concentration of curcumin in raw Curcuma longa. L. Food Res. 2018; 2: 500-4.

34. Gounder DK, Lingamallu J. Comparison of chemical composition and antioxidant potential of volatile oil from fresh, dried and cured turmeric (Curcuma longa) rhizomes. Ind. Crops Prod. 2012; 38: 124-31.

35. Dobreva A, Kovatcheva N, Astatkie T, Zheljazkov VD. Improvement of essential oil yield of oil-bearing (Rosa damascena Mill.) due to surfactant and maceration. Ind. Crops Prod. 2011; 34(3): 1649-51.

36. Kifelew H, Bekele D, Yadesa L, Getu A, Getachew W, Hailemichael G, Mitiku H. Result of Turmeric Variety Trial in Ethiopia. Intern. J. Res. Stud. Agricul. Stud. 2018; 4(9): 34-8.

37. Padma M, Reddy B, Madhava M. Evaluation of the quality parameters of the turmeric rhizomes dried on different floors and conditions. Internat. J. Agric. Sci. 2016; 12: 302-08.

2021 by the authors. Submitted for possible open access publication under the terms and conditions of the Creative Commons Attribution (CC BY NC) license (https://creativecommons.org/licenses/by-nc/4.0/). 